\title{
Chemoprevention of Colonic Polyps with Balsalazide: An Exploratory, Double-Blind, Placebo-Controlled Study
}

\author{
Jonathan P. Terdiman • Lorin K. Johnson · Young S. Kim • \\ Marvin H. Sleisenger · James R. Gum Jr. • Ann Hayes • \\ Vivian K. Weinberg · Kenneth R. McQuaid
}

Received: 2 April 2009/Accepted: 20 August 2009/Published online: 11 September 2009

(c) The Author(s) 2009. This article is published with open access at Springerlink.com

\begin{abstract}
Backgroud A number of agents, including aspirin, nonsteroidal antiinflammatory drugs, cyclooxygenase-2 inhibitors, folic acid, calcium, and vitamins, have been evaluated for their potential in chemoprevention of sporadic colorectal adenomas or cancer. Preclinical data suggest that 5-aminosalicylates also may have a chemopreventive effect.

Aim To investigate chemoprevention of colonic polyps with balsalazide, a 5-aminosalicylate prodrug.

Methods In this randomized, double-blind, placebocontrolled study, adults diagnosed with small polyps in the rectosigmoid colon were treated with either balsalazide $3 \mathrm{~g} / \mathrm{d}$ or placebo for 6 months. Follow-up lower endoscopy was performed, and all polyps were measured and analyzed
\end{abstract}

James R. Gum, Jr, Ph.D., died after the conclusion of the study and during the preparation of the manuscript. However, his contributions to the study merit his inclusion as a co-author.

J. P. Terdiman $(\bowtie) \cdot$ Y. S. Kim · M. H. Sleisenger .

J. R. Gum Jr. · A. Hayes - K. R. McQuaid

Division of Gastroenterology, Department of Medicine,

University of California, San Francisco, San Francisco,

CA, USA

e-mail: Jonathan.Terdiman@ucsf.edu

L. K. Johnson

Salix Pharmaceuticals, Inc, Morrisville, NC, USA

Y. S. Kim - M. H. Sleisenger · J. R. Gum Jr. · A. Hayes ·

K. R. McQuaid

Department of Veterans Affairs Medical Center, San Francisco,

CA, USA

V. K. Weinberg

Helen Diller Family Cancer Center Biostatistics Core, University

of California, San Francisco, Box 1623, San Francisco,

CA 94143, USA histologically. The primary endpoint was reduction in mean size of the largest polyp per subject.

Results Among 241 participants screened, 86 were randomized to treatment, with 75 subjects evaluable. Balsalazide $3 \mathrm{~g} / \mathrm{d}(n=38)$ did not significantly reduce the mean size of the largest colonic polyp or the number of polyps compared with placebo $(n=37)$. Although not significant, post-hoc analysis revealed that total adenoma burden per subject, calculated as the sum of the volumes of all adenomas in $\mathrm{mm}^{3}$, increased by $55 \%$ in the balsalazide group compared with $95 \%$ in the placebo group.

Conclusions Although balsalazide did not have significant chemopreventive effects on established colonic polyps, these results can aid in designing future prospective studies.

Keywords Balsalazide - 5-Aminosalicylic acid . Chemoprevention - Colonic adenoma - Colonic polyp . Colorectal cancer

\section{Introduction}

Colorectal cancer is the second leading cause of malignancyrelated deaths in the United States [1, 2]. In 2007, an estimated 52,000 deaths will result from the disease, and more than 150,000 new cases will be diagnosed [3]. Most colorectal cancers $(>95 \%)$ arise from adenomatous polyps (adenomas) [4, 5]. Adenomas with diameters $<1 \mathrm{~cm}$ are common and have a low risk of malignancy, in contrast with larger adenomas (diameter $>1 \mathrm{~cm}$ ), which have a substantially greater risk of becoming malignant and progressing to cancer [2, 4-6]. Mortality from colorectal cancer can be reduced by routine screening of individuals aged 50 years and older by colonoscopy, flexible sigmoidoscopy, and other 
techniques $[1,2,7]$. The focus of colorectal cancer screening is the reliable detection of large or advanced adenomas before they become malignant $[5,7]$.

Several agents, including nonsteroidal antiinflammatory drugs (NSAIDs; e.g., aspirin, aminosalicylates, cyclooxygenase-2 (COX-2) inhibitors), folic acid, calcium, and vitamins, have been evaluated for their potential in chemoprevention of colorectal cancer [5, 8-12]. The administration of chemopreventive agents may reduce the incidence of colorectal cancer, and these agents may act by inhibiting cell hyperproliferation, enhancing apoptosis, blocking the accumulation of carcinogenic mutations, or otherwise slowing the progression from neoplasia to malignancy [9].

5-Aminosalicylates (5-ASAs), first-line treatment for mild-to-moderate ulcerative colitis, have not been evaluated in the chemoprevention of sporadic colorectal cancer or colonic adenomas. However, patients with inflammatory bowel disease are at increased risk of developing colorectal cancer [13, 14], and 5-ASAs have been shown in retrospective studies to reduce the incidence of dysplasia in patients with ulcerative colitis [10, 14-20]. However, the efficacy of 5-ASA in colitis-related colorectal cancer prevention is unclear; some reports demonstrate an association between early 5-ASA administration and reducing the risk of developing colorectal cancer [10, 15, 17-20] whereas others fail to establish such an association [14, 16]. In addition to its antiinflammatory properties, the putative chemopreventive effect of 5-ASA may be connected to its ability to induce apoptosis of tumor cells [21] or its ability to affect cell cycle progression and improve DNA replication fidelity [22].

The 5-ASA prodrug balsalazide has demonstrated efficacy in the treatment of active [23, 24] and quiescent [25, 26] ulcerative colitis and has been evaluated in established animal models of colon carcinogenesis [27]. In the Min mouse model, in which animals are genetically susceptible to intestinal tumor formation, administration of balsalazide achieved a reduction of up to $80 \%$ in the number of tumors observed compared with the control group [27]. Additionally, in rats in which aberrant intestinal crypts were chemically induced, balsalazide treatment significantly reduced the numbers of aberrant crypt foci by $60 \%$ compared with controls [27]. Therefore, investigation of the efficacy of balsalazide in human colorectal cancer chemoprevention was warranted. The chemopreventive effects of 5-ASA could presumably inhibit either the development of dysplasia, the subsequent growth of dysplastic cells, or both. This exploratory study is the first prospective clinical study published that tested the second of these two potential mechanisms by comparing the effect of balsalazide versus placebo in reducing the size and number of colonic polyps initially identified during routine screening by flexible sigmoidoscopy.

\section{Methods}

Subjects

Subjects aged 45-80 years, who were scheduled to undergo lower endoscopy (flexible sigmoidoscopy or colonoscopy) for colorectal cancer screening and in whom polyps measuring between 3 and $9 \mathrm{~mm}$ in diameter were detected in the rectosigmoid colon, were included in this prospective, randomized, double-blind, placebo-controlled study. Exclusion criteria included any prior history of colitis, colon cancer, colonic resection, familial adenomatous polyposis, hereditary nonpolyposis colon cancer (Lynch syndrome), or any other malignancy; detection of polyps $>9 \mathrm{~mm}$ in diameter; administration of anticoagulants, corticosteroids, immunosuppressive agents, or NSAIDs during the study; and the presence of specific problems that may increase the risk associated with colonoscopy or mucosal biopsy (i.e, prosthetic heart valves, requirement of antibiotic prophylaxis, platelet count $<50,000 / \mathrm{mm}^{3}$, myocardial infarction in the past three months, coagulopathy, severe congestive heart failure, chronic obstructive pulmonary disease, or unstable coronary artery disease). Initially aspirin was excluded as a concomitant medication. However, the high percentage of subjects at the study site receiving low-dose aspirin made recruitment difficult. Therefore, the protocol was amended to allow concomitant aspirin use $(\leq 325 \mathrm{mg} / \mathrm{d})$, and randomization was stratified by concomitant aspirin use. The study was performed at the San Francisco Veterans Affairs Medical Center. The study was approved by the institutional review board and all subjects provided written informed consent.

\section{Screening and Treatment}

At the initial screening visit, subjects underwent regularly scheduled endoscopy, and polyps between 3 and $9 \mathrm{~mm}$ in diameter in the rectosigmoid colon (within $50 \mathrm{~cm}$ of the anal verge) were photographed, measured using the open biopsy forceps method, and their distance from the anal verge recorded. Mucosa adjacent to the polyps was tattooed with India ink to facilitate re-identification at follow-up endoscopy. Polyps were not biopsied during the initial endoscopy, so histological assessment of the polyps at study enrollment was not possible. Biopsies of normal rectal mucosa were taken for analysis of apoptosis. Participants were randomized to receive either balsalazide (Colazal; Salix Pharmaceuticals, Morrisville, NC, USA) 3 g/d (two 750-mg capsules twice daily) or placebo for 6 months. Participants returned for follow-up visits after 1, 3, and 5 months to determine treatment compliance based on pill counts, administration of any concomitant medications, and the occurrence of any adverse events. Following 6 months 
of treatment, participants underwent a second lower endoscopy (complete colonoscopy if initial exam was a flexible sigmoidoscopy and vice versa). All previously tattooed rectosigmoid polyps, and any new rectosigmoid polyps, were measured and then completely removed and sent for histological analysis. Polyps observed proximal to the rectosigmoid colon (i.e., $>50 \mathrm{~cm}$ from the anal verge) were removed but were not part of the analysis. Biopsies of normal-appearing rectal mucosa again were taken. The same endoscopist performed the initial and follow-up endoscopies.

\section{Assessments}

The primary study efficacy endpoint was reduction in mean size of the largest rectosigmoid polyp per subject at 6 months. Secondary endpoints included reduction in total number of polyps, reduction in mean size of adenomatous polyps, reduction in the proportion of subjects with an increase in adenomatous polyp size, reduction in total adenoma burden, and change in apoptotic index of rectal mucosa. Adenoma burden was assessed at baseline and follow-up by summing the calculated volumes of all of the adenomas using the measured diameters of the polyps and assuming the polyps to be spherical.

Eight rectal mucosal pinch biopsies from normal tissue were obtained before randomization and after 6 months of treatment. Apoptotic cells were detected by the terminal deoxynucleotidyl transferase-mediated dUTP nick end labeling (TUNEL) method [28] using terminal transferase to enzymatically incorporate digoxigenin-labeled nucleotides into the $3^{\prime}$-terminus of the fragmented DNA characteristic of apoptotic cells, followed by the detection of incorporated label using standard immunohistochemical techniques. Apoptotic indices were then determined by scoring 1,000 rectal epithelial cells for TUNEL positivity.

\section{Statistical Analysis}

A total sample size of 200 subjects was planned in order to provide $80 \%$ power to detect a $20 \%$ change in the mean size of the largest polyp per subject between the two treatment groups. Because of difficulty in recruitment, even with expanding eligibility to include subjects taking aspirin, the total planned accrual was not achieved. After 86 subjects had been randomized, a decision was made to stop further enrollment and to perform an interim data analysis. Based on this analysis, it became clear that it would not be possible to reject the null hypothesis and detect a $20 \%$ change in mean polyp size with the planned $80 \%$ power even if the initial enrollment target was met, so a decision was made to terminate the study. Comparability of the two treatment groups at randomization was analyzed using the chi-square statistic for categorical variables and a $t$ statistic for continuous variables. Similar analyses using a $t$ statistic were carried out to determine a difference in mean change in polyp size due to treatment. Changes between the two study arms in apoptotic indices of rectal mucosa were also analyzed with the same methods.

\section{Results}

\section{Subject Population}

Among the 241 subjects screened after providing informed consent, 86 subjects with rectosigmoid polyps between 3 and $9 \mathrm{~mm}$ were randomized to receive balsalazide $3 \mathrm{~g} / \mathrm{d}$ ( $n=44$ ) or placebo ( $n=42$; Fig. 1$)$. Of the 86 randomized subjects, 75 completed the study (38 in the balsalazide group and 37 in the placebo group) and had polyps that could be compared at baseline and at the end of treatment, and were therefore included in the evaluable population (Table 1). The non-evaluable study subjects all withdrew consent to participate in the study after randomization and therefore did not take study medication. The subjects were all male, and mean age was comparable between groups. All of the evaluable subjects took $>80 \%$ of their study medications, and there was no difference in adherence between groups. The India ink tattoos were identified in all study subjects except one who had been treated with placebo and in whom the baseline polyp was not visible at follow-up exam. The mean number of polyps per subject and the mean size of the largest polyp per subject did not differ significantly at baseline between treatment groups. There was, however, a significant difference $(P=0.03)$ in distribution of polyp histologic type between groups. Polyps detected at baseline in the subjects randomized to balsalazide treatment were more frequently identified as adenomas upon histologic examination (26 of 56 polyps; $46 \%$ ) compared with placebo-treated subjects (13 of 53 polyps; $25 \%$ ). In addition, the proportion of subjects with at least one adenoma at baseline was higher for the balsalazide group than for the placebo group (68 vs. $43 \%$, respectively; $P=0.04$ ).

Primary Analysis: Change in Mean Size of Largest Polyp Per Subject

After 6 months of treatment, marked polyps were remeasured and removed for histologic analysis. For the primary study endpoint, there was no significant difference between groups in the mean change in diameter of the largest polyp per subject after 6 months of treatment (Table 2). For balsalazide-treated subjects, the mean 


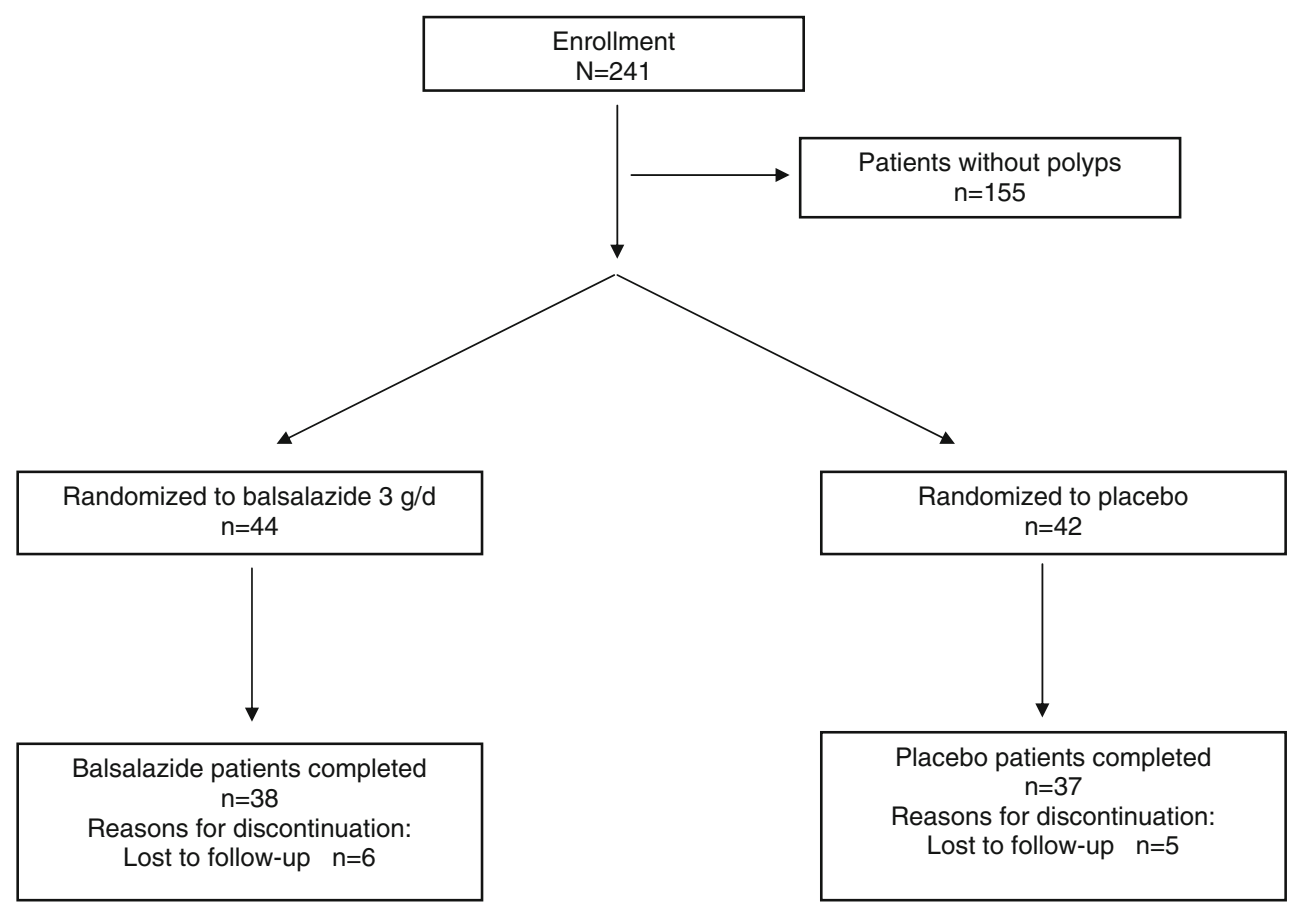

Fig. 1 Flow of patients through the study. Patients in whom polyps were detected by colonoscopy were randomized for inclusion in the study

Table 1 Subject demographics and baseline polyp characteristics for evaluable population

$S D$ standard deviation, $N S$ not significant

\begin{tabular}{|c|c|c|c|}
\hline & $\begin{array}{l}\text { Balsalazide } \\
3 \mathrm{~g} / \mathrm{d}(n=38)\end{array}$ & $\begin{array}{l}\text { Placebo } \\
(n=37)\end{array}$ & $P$ value \\
\hline Mean age $(y \pm \mathrm{SD})$ & $63 \pm 12$ & $63 \pm 13$ & NS \\
\hline Reporting concomitant aspirin use, $n(\%)$ & $17(45)$ & $15(41)$ & NS \\
\hline \multicolumn{4}{|l|}{ Mean number of polyps/subject $(n \pm S D)$} \\
\hline All evaluable subjects & $1.9 \pm 1.5$ & $1.9 \pm 1.1$ & NS \\
\hline Receiving concomitant aspirin & $2.0 \pm 1.0$ & $1.3 \pm 0.6$ & 0.02 \\
\hline No concomitant aspirin & $1.8 \pm 1.8$ & $2.3 \pm 1.1$ & NS \\
\hline Range of number of polyps/subject & $1-9$ & $1-4$ & \\
\hline \multicolumn{4}{|l|}{ Subjects with $>1$ polyp, $n(\%)$} \\
\hline All evaluable subjects & $17(45)$ & $18(49)$ & NS \\
\hline Receiving concomitant aspirin & $10(59)$ & $3(21)$ & 0.04 \\
\hline No concomitant aspirin & $7(21)$ & $15(68)$ & 0.03 \\
\hline \multicolumn{4}{|l|}{ Mean size of largest polyp/subject $(m m \pm S D)$} \\
\hline All evaluable subjects & $5.5 \pm 1.7$ & $5.4 \pm 1.9$ & NS \\
\hline Receiving concomitant aspirin & $6.1 \pm 2.0$ & $5.0 \pm 1.9$ & NS \\
\hline No concomitant aspirin & $5.0 \pm 1.4$ & $5.7 \pm 1.8$ & NS \\
\hline \multicolumn{4}{|l|}{ At 6-month follow-up } \\
\hline \multicolumn{4}{|l|}{ Polyp histology, number of subjects } \\
\hline Hyperplastic & 8 & 19 & \\
\hline Adenomatous & 14 & 7 & 0.03 \\
\hline Both & 12 & 9 & \\
\hline \multicolumn{4}{|c|}{ Subjects with $\geq 1$ adenoma at follow-up, $n / N(\%)$} \\
\hline All evaluable subjects & $26 / 38(68)$ & $16 / 37(43)$ & 0.04 \\
\hline Receiving concomitant aspirin & $13 / 17(76)$ & $5 / 15(33)$ & 0.03 \\
\hline No concomitant aspirin & $13 / 21(62)$ & $11 / 22(50)$ & NS \\
\hline $\begin{array}{l}\text { Subjects with no initial adenomas but } \\
\geq 1 \text { adenoma at follow-up, } n / N(\%)\end{array}$ & 4/38 (11) & $3 / 37(8)$ & NS \\
\hline
\end{tabular}


Table 2 Effect of 6 months of treatment on polyp growth

\begin{tabular}{|c|c|c|c|c|c|}
\hline \multirow[t]{2}{*}{ Assessment } & \multicolumn{2}{|c|}{ Balsalazide $3 \mathrm{~g} / \mathrm{d}$} & \multicolumn{2}{|c|}{ Placebo } & \multirow[t]{2}{*}{$P$ value } \\
\hline & $n$ & $\mathrm{~mm} \pm \mathrm{SD}$ & $n$ & $\mathrm{~mm} \pm \mathrm{SD}$ & \\
\hline \multicolumn{6}{|c|}{ Largest polyp: change in mean size after 6 months } \\
\hline All evaluable subjects & 38 & $0.2 \pm 1.5$ & 37 & $-0.5 \pm 2.2$ & NS \\
\hline Receiving concomitant aspirin & 17 & $0.06 \pm 1.2$ & 15 & $-0.53 \pm 2.5$ & NS \\
\hline No concomitant aspirin & 21 & $0.30 \pm 1.7$ & 22 & $-0.45 \pm 2.0$ & NS \\
\hline \multicolumn{6}{|c|}{ Largest adenoma: change in mean size after 6 months } \\
\hline All evaluable subjects & 22 & $0.3 \pm 1.6$ & 13 & $0.5 \pm 1.7$ & NS \\
\hline Receiving concomitant aspirin & 13 & $-0.1 \pm 1.2$ & 5 & $0.8 \pm 1.6$ & NS \\
\hline No concomitant aspirin & 9 & $0.8 \pm 2.0$ & 8 & $0.3 \pm 1.8$ & NS \\
\hline
\end{tabular}

$S D$ standard deviation, $N S$ not significant

Table 3 New or missing polyps detected after 6 months of treatment

$S D$ standard deviation

\begin{tabular}{lll}
\hline Assessment & $\begin{array}{l}\text { Balsalazide } \\
3 \mathrm{~g} / \mathrm{d}(n=38)\end{array}$ & $\begin{array}{l}\text { Placebo } \\
(n=37)\end{array}$ \\
\hline Subjects with new polyps with histology at 6 months $(n)$ & 17 & 18 \\
$\quad$ Hyperplastic only & 4 & 4 \\
Tubular adenoma only & 8 & 12 \\
Both & 5 & \\
Mean size of new polyps (mm \pm SD) & & $3.7 \pm 1.6$ \\
Hyperplastic & $3.2 \pm 1.5$ & $6.2 \pm 5.1$ \\
Tubular adenoma & $5.2 \pm 1.7$ & $5.0(n=1)$ \\
Mean size of new adenomas (mm) & & $6.4(n=5)$ \\
$\quad$ Receiving concomitant aspirin & $5.3(n=3)$ & \\
$\quad$ No concomitant aspirin & $5.1(n=6)$ & $4(2 ; 2)$ \\
Polyps not detected at 6-month follow-up visit & & $5.2(n=5)$ \\
Subjects, $n$ (aspirin; no aspirin) & $3(2 ; 1)$ & $3.4(n=5)$ \\
$\quad$ Mean size at baseline (mm) & & \\
\hline
\end{tabular}

change in the size of the largest polyp was $0.2 \pm 1.5 \mathrm{~mm}$. For placebo-treated subjects, the mean change in the size of the largest polyp was $-0.5 \pm 2.2 \mathrm{~mm}$. Similar results were observed regardless of whether subjects were receiving concomitant aspirin therapy.

\section{Change in Polyp Number}

There was no significant difference in the change in total polyp number at follow-up between treatment groups. The missed or new polyp rate (i.e., histologically identified polyps at follow-up but not marked at baseline) was similar between the two groups. In the balsalazide group, 17 subjects presented at the 6-month follow-up visit with polyps not identified at baseline; similarly, in the placebo group, 18 subjects presented at follow-up with polyps not identified at baseline (Table 3 ). When these newly identified polyps were added to the originally identified and marked polyps, the missed and/or new polyp proportion was calculated to be $30.8 \%$ in the balsalazide group and $30.2 \%$ in the placebo group. Similarly, there was no difference in the number of polyps which were detected at baseline, but then not detected at the follow-up exam, between groups (three polyps in the balsalazide group and four in the placebo group, Fisher's exact test: $P=1.0$ ).

Secondary Analysis: Change in Adenoma Size

All adenomatous polyps removed were tubular adenomas. Overall, there was no difference in the mean change in size of the largest adenomatous polyps when comparing balsalazide-treated subjects with those receiving placebo (Table 2). Among subjects who received aspirin concomitantly, adenomas identified in subjects treated with balsalazide showed a smaller size increase per subject compared with adenomas identified in subjects treated with placebo, but this difference was not significant (Table 2).

Among subjects who presented at follow-up with new adenomas, the mean size of all newly identified adenomas did not differ between treatment groups (Table 3). Among 
subjects not taking concomitant aspirin, new adenomas were smaller among those given balsalazide compared with placebo, but this difference did not reach significance.

\section{Secondary Analysis: Apoptotic Markers}

To determine if balsalazide treatment would affect the rate of apoptosis, the change from baseline in the apoptotic index in rectal mucosa was assessed after 6 months of treatment. Increased TUNEL was detected in $70 \%$ of balsalazide-treated subjects compared with $58 \%$ of placebo-treated subjects (Fig. 2). In addition, a nonsignificant trend in favor of balsalazide was observed in the magnitude of the mean change in apoptotic index (balsalazide, $0.99 \pm 2.58$; placebo, $0.38 \pm 1.04$ ).

\section{Exploratory Analysis: Total Adenoma Burden}

Among subjects who received balsalazide, the mean adenoma burden per subject at baseline was 157.0 versus $128.9 \mathrm{~mm}^{3}$ for subjects receiving placebo. Following treatment, these increased to 189.3 and $184.6 \mathrm{~mm}^{3}$, respectively. This resulted in a mean increased adenoma burden of 55\% for those treated with balsalazide compared with a mean increased adenoma burden of $95 \%$ for the placebo-treated subjects. This difference was because of a greater, although non-significant, increase in the mean burden in placebo-treated subjects compared with balsalazide-treated subjects (Table 4).

\section{Safety}

Balsalazide was well tolerated in this study, and no significant differences in incidence of adverse events were reported between the two treatment groups.

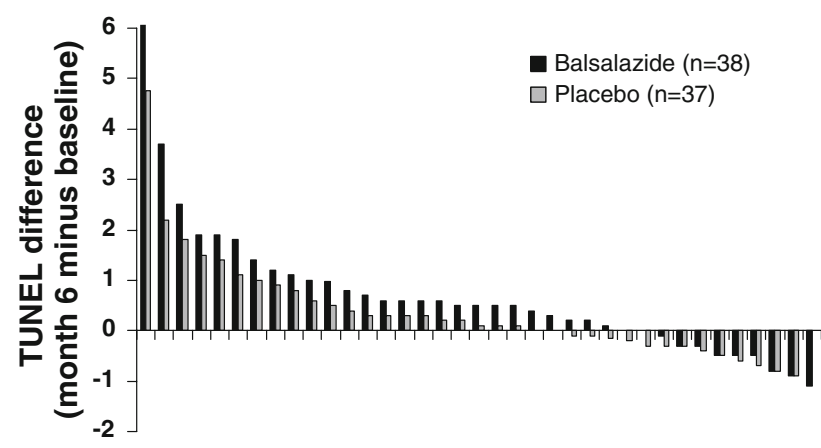

Fig. 2 Change from baseline in TUNEL apoptotic index after 6 months of treatment with balsalazide $3 \mathrm{~g} / \mathrm{d}(n=38)$ or placebo $(n=37)$. Bars represent the change from baseline for each subject. TUNEL, terminal deoxynucleotidyl transferase-mediated dUTP nick end labeling
Table 4 Adenoma burden before and after 6 months of treatment

\begin{tabular}{|c|c|c|}
\hline Assessment & $\begin{array}{l}\text { Balsalazide } \\
3 \mathrm{~g} / \mathrm{d} \\
(n=22)\end{array}$ & $\begin{array}{l}\text { Placebo } \\
(n=13)\end{array}$ \\
\hline $\begin{array}{l}\text { Burden per subject at baseline } \\
\left(\mathrm{mm}^{3} \pm \mathrm{SD}\right)\end{array}$ & $157.0 \pm 110.9$ & $128.8 \pm 89.3$ \\
\hline $\begin{array}{l}\text { Burden per subject at } 6 \text { months } \\
\left(\mathrm{mm}^{3} \pm \mathrm{SD}\right)\end{array}$ & $189.3 \pm 130.4$ & $184.6 \pm 145.8$ \\
\hline $\begin{array}{l}\text { Change of mean burden } \\
\quad\left(\mathrm{mm}^{3} \pm \mathrm{SD}\right)\end{array}$ & $32.3 \pm 130.5$ & $55.7 \pm 102.5$ \\
\hline Mean of per subject change $(\%)$ & $+55.7 \%$ & $+95.0 \%$ \\
\hline Burden increase ( $N$, mean $\%$ change) & $9(+166 \%)$ & $6(+222 \%)$ \\
\hline Burden no change ( $N, \%$ change) & $8(0)$ & $5(0)$ \\
\hline Burden decrease ( $N, \%$ change) & $5(-56.5 \%)$ & $2(-47.2 \%)$ \\
\hline
\end{tabular}

Includes only subjects with both baseline and 6-month measurements $S D$ standard deviation

\section{Discussion}

Agents that can prevent the growth of polyps, reduce their size, or cause their complete regression are likely to help reduce the risk for development of colorectal cancer [4]. Thus, a reduction in adenoma size or number serves as a surrogate marker for chemoprevention of colorectal cancer [11]. Because salicylates such as aspirin have shown positive correlations with reduced colorectal cancer incidence [8], the well-tolerated 5-aminosalicylate prodrug balsalazide was prospectively evaluated for its ability to reduce the size and/or number of established, diminutive polyps over a 6-month treatment period. 5-Aminosalicylates may well prevent the development of dysplasia in patients with longstanding ulcerative colitis [29], but their ability to prevent sporadic colorectal neoplasia in humans has not been studied.

Although the rationale for this randomized, doubleblind, placebo-controlled, exploratory study was sound, the major endpoints of the study were not achieved. No significant difference in the mean change in size of the largest polyp, nor in the total number of polyps, was detected between subjects who received balsalazide or placebo over 6 months.

It should be noted, however, that the primary endpoint of this study considered all identified polyps regardless of histologic type. However, even when the analyses were confined to only tubular adenomas, no clear difference in the mean change of size or number of adenomas was seen between treatment groups. Thus, the results do not support the hypothesis that balsalazide treatment for 6 months is able to reduce the size of existing, diminutive colorectal polyps as defined in this prospective analysis plan.

It should be considered whether this result is because the study sample size was insufficient for detection of the 
proposed difference for the specified type II error, or whether or not an inability to measure polyp size with sufficient accuracy would preclude our ability to assess the primary endpoint. A total population of 200 had been planned in order to detect a $20 \%$ change in the mean size of the largest polyp per subject with balsalazide compared with placebo. Given that the mean size of the baseline polyps was $5-6 \mathrm{~mm}$, a $20 \%$ change in size would be approximately $1-1.2 \mathrm{~mm}$. In terms of measurement accuracy, we used a standard methodology and we feel confident that we are able to accurately detect changes in size of $1 \mathrm{~mm}$ or more in polyp size. However, no gold standard exists for polyp measurement in situ, and we have no way of unequivocally demonstrating the accuracy and precision of our measurements. In terms of sample size, the target was not achieved, because of slow enrollment. However, after analyzing the data from 75 evaluable subjects, the mean size of the largest polyp in the placebo group decreased by $7.2 \%$ whereas the mean size of the largest polyp in the balsalazide-treated subjects increased by $4.5 \%$. Therefore, it is very unlikely that the primary endpoint of the study would have been achieved even if the target enrollment had been met. In addition, no difference between groups was noted for the easier to assess endpoint of change in polyp number. We conclude, therefore, that the neither the small sample size, nor the accuracy of our polyp measurements, affected our finding that balsalazide does not cause a clinically important retardation or regression of growth in diminutive polyps.

Adenoma growth, not polyp growth, is the better endpoint to assess the colorectal cancer chemopreventive effect of a drug. The analysis of changes in adenoma size over time is complicated by the fact that a marked polyp can:

1 increase in size;

2 not change in size; or

3 decrease in size.

Unfortunately, an analysis that is focused only on the mean change in size per subject in the entire group fails to account for the possibility that these three types of outcomes can counteract each other in the analysis and greatly increase the standard deviation, possibly resulting in a smaller observed effect size.

To attempt to overcome this limitation, an exploratory analysis examined the overall adenoma burden per subject. This takes into account all potential neoplastic tissue identified and is not limited to the largest adenoma only. This analysis showed that subjects given placebo had a greater, though non-significant, increase in adenoma burden than those treated with balsalazide. This observation suggests, though in no way confirms, that balsalazide may retard adenoma growth.
The study design also limited the ability to determine if balsalazide has a chemopreventive effect regarding sporadic colorectal neoplasia. The analysis was limited to subjects with small polyps in the distal colon, the treatment duration was only 6 months, and the dose of balsalazide was set at $3 \mathrm{~g}$ per day. The reason for limiting the analysis to subjects with small polyps in the distal colon was because most of the subjects underwent a flexible sigmoidoscopy as their initial exam. Therefore no baseline assessment was undertaken of the proximal colon. In addition, it was felt to be unsafe to leave polyps greater than $9 \mathrm{~mm}$ in situ for 6 months, or to allow subjects with distal polyps of this size to wait 6 months to have an endoscopic evaluation of their proximal colons. The dose of balsalazide employed in the study was based on preclinical data, dosing convenience, and dose-response data for the maintenance of remission in ulcerative colitis [2527]. We acknowledge that the ability of balsalazide to prevent the occurrence or recurrence of colorectal neoplasia was not studied, nor was the effect of balsalazide on larger or more advanced or more proximal neoplasias, nor was the effect of higher doses of balsalazide. The study design employed was chosen to maximize safety and to minimize study duration and cost and has been successful in demonstrating the chemopreventive actions of NSAIDs and COX-2 inhibitors in patients with familial adenomatous polyposis [30, 31].

The potential chemopreventive action of balsalazide or other 5-ASAs in colorectal neoplasia has been suggested by preclinical studies [27], although the potential chemopreventive mechanism remains unclear. Although only a small, nonsignificant increase in TUNEL of rectal biopsies was observed in the balsalazide group compared with the placebo group in this study, this positive trend was consistent with reports of the proapoptotic effect of 5-ASAs on colonic epithelial cells in vitro [27]. Several studies suggest a multiplicity of actions that may contribute to the possible chemopreventive actions of 5-ASA (reviewed by Rubin et al. [29]). These include functioning as a peroxisome proliferator-activated receptor $\gamma$ agonist and as a factor involved in the maintenance of intestinal mucosal integrity [32], DNA replication fidelity [33], and cell cycle accumulation in the $\mathrm{S}$ phase [22]. These actions contribute to a more controlled, less proliferative population of epithelial cells in the colonic mucosa, and contribute to the induction of apoptosis in dysplastic cells. It is very unlikely that COX-2 inhibition is the primary mechanism of 5-ASA action. 5-Aminosalicylates are weak direct inhibitors of COX-2, unlike ASA and NSAIDs; however, they are potent inhibitors of the transcription factor nuclear factor-kappa B $(\mathrm{NF}-\kappa \mathrm{B})$. Recent preclinical data suggest that $\mathrm{NF}-\kappa \mathrm{B}$ may play an important role in the development of colorectal neoplasia, possibly through upstream induction of COX-2, increased 
prostaglandin E2 production, and activation of epidermal growth factor receptor signaling [34].

In conclusion, this study failed to show that balsalazide $3 \mathrm{~g} / \mathrm{d}$ for 6 months could reduce the size or number of diminutive colonic polyps. Nor was there evidence of balsalazide reducing the size or number of colonic adenomas. However, the greater increase in adenoma burden among subjects receiving placebo compared with balsalazide, in conjunction with mechanistic and preclinical data, still suggest that 5-ASA agents such as balsalazide might be effective in preventing or slowing the growth of colorectal neoplasia. To fully explore the ability of balsalazide to prevent or slow the progression of colonic adenomas or colorectal cancer, larger and longer prospective studies with a different study design will need to be undertaken.

Acknowledgments This study was supported by an investigatorinitiated grant from the California Cancer Research Program, a grant from the Theodora Betz Foundation, and funding from Salix Pharmaceuticals, Inc.

Dr Terdiman had full access to all the data in the study and takes responsibility for the integrity of the data and the accuracy of the data analysis.

Study concept and design: Terdiman, Johnson, Kim, Sleisenger, Gum, Weinberg, McQuaid; Acquisition of the data: Terdiman, Gum, Hayes, McQuaid; Analysis and interpretation of the data: Terdiman, Johnson, Kim, Sleisenger, Gum, Hayes, Weinberg, McQuaid; Drafting of the manuscript: Terdiman, Johnson; Critical revision of the manuscript: Terdiman, Johnson, Kim, Sleisenger, Weinberg, McQuaid; Statistical analysis: Weinberg; Obtained funding: Johnson, Kim, Sleisenger; Administrative, technical or material support: Gum, Hayes; Study supervision: Terdiman, Johnson, McQuaid.

Potential Competing Interests Dr. Johnson is an employee of Salix Pharmaceuticals, Inc. Dr. Sleisenger serves as a consultant to Salix Pharmaceuticals, Inc. No other conflicts of interest identified.

Open Access This article is distributed under the terms of the Creative Commons Attribution Noncommercial License which permits any noncommercial use, distribution, and reproduction in any medium, provided the original author(s) and source are credited.

\section{References}

1. Walsh JM, Terdiman JP. Colorectal cancer screening: scientific review. JAMA. 2003;289:1288-1296.

2. Bond JH. Colorectal cancer update. Prevention, screening, treatment, and surveillance for high-risk groups. Med Clin North Am. 2000;84:1163-1182.

3. Jemal A, Siegel R, Ward E, Murray T, Xu J, Thun MJ. Cancer statistics, 2007. CA Cancer J Clin. 2007;57:43-66.

4. Winawer SJ, Zauber AG, Fletcher RH, et al. Guidelines for colonoscopy surveillance after polypectomy: a consensus update by the US multi-society task force on colorectal cancer and the American cancer society. CA Cancer J Clin. 2006;56:143-159.

5. Bond JH. Polyp guideline: diagnosis, treatment, and surveillance for patients with colorectal polyps. Am J Gastroenterol. 2000;95:
3053-3063. For the practice parameters committee of the American college of gastroenterology.

6. Atkin WS, Morson BC, Cuzick J. Long-term risk of colorectal cancer after excision of rectosigmoid adenomas. $N$ Engl $\mathrm{J}$ Med. 1992;326:658-662.

7. Winawer SJ. Colorectal cancer screening. Best Pract Res Clin Gastroenterol. 2007;21:1031-1048.

8. Dubé C, Rostom A, Lewin G, et al. The use of aspirin for primary prevention of colorectal cancer: a systematic review prepared for the US preventive services task force. Ann Intern Med. 2007;146: 365-375.

9. Krishnan K, Brenner DE. Chemoprevention of colorectal cancer. Gastroenterol Clin North Am. 1996;25:821-858.

10. Bernstein CN, Eaden J, Steinhart AH, Munkholm P, Gordon PH. Cancer prevention in inflammatory bowel disease and the chemoprophylactic potential of 5-aminosalicylic acid. Inflamm Bowel Dis. 2002;8:356-361.

11. Hawk ET, Umar A, Viner JL. Colorectal cancer chemoprevention-an overview of the science. Gastroenterology. 2004;126: $1423-1447$.

12. Rostom A, Dubé C, Lewin G, et al. Nonsteroidal anti-inflammatory drugs and cyclooxygenase- 2 inhibitors for primary prevention of colorectal cancer: a systematic review prepared for the US preventive services task force. Ann Intern Med. 2007;146:376-389.

13. Eaden JA, Abrams KR, Mayberry JF. The risk of colorectal cancer in ulcerative colitis: a meta-analysis. Gut. 2001;48:526-535.

14. Terdiman JP, Steinbuch M, Blumentals WA, Ullman TA, Rubin DT. 5-Aminosalicylic acid therapy and the risk of colorectal cancer among patients with inflammatory bowel disease. Inflamm Bowel Dis. 2007;13:367-371.

15. Velayos FS, Terdiman JP, Walsh JM. Effect of 5-aminosalicylate use on colorectal cancer and dysplasia risk: a systematic review and metaanalysis of observational studies. Am J Gastroenterol. 2005; 100:1345-1353.

16. Bernstein CN, Blanchard JF, Metge C, Yogendran M. Does the use of 5-aminosalicylates in inflammatory bowel disease prevent the development of colorectal cancer? Am J Gastroenterol. 2003;98: 2784-2788.

17. Ryan BM, Russel MGVM, Langholz E, Stockbrugger RW. Aminosalicylates and colorectal cancer in IBD: a not-so bitter pill to swallow. Am J Gastroenterol. 2003;98:1682-1687.

18. Eaden J. Review article: the data supporting a role for aminosalicylates in the chemoprevention of colorectal cancer in patients with inflammatory bowel disease. Aliment Pharmacol Ther. 2003; 18(Suppl 2):15-21.

19. Eaden J, Abrams K, Ekbom A, Jackson E, Mayberry J. Colorectal cancer prevention in ulcerative colitis: a case-control study. Aliment Pharmacol Ther. 2000;14:145-153.

20. van Staa TP, Card T, Logan RF, Leufkens HG. 5-Aminosalicylate use and colorectal cancer risk in inflammatory bowel disease: a large epidemiological study. Gut. 2005;54:1573-1578.

21. Bus PJ, Nagtegaal ID, Verspaget HW, et al. Mesalazine-induced apoptosis of colorectal cancer: on the verge of a new chemopreventive era? Aliment Pharmacol Ther. 1999;13:1397-1402.

22. Luciani MG, Campregher C, Fortune JM, Kunkel TA, Gasche C. 5-ASA affects cell cycle progression in colorectal cells by reversibly activating a replication checkpoint. Gastroenterology. 2007;132:221-235.

23. Green JRB, Lobo AJ, Holdsworth CD, et al. Balsalazide is more effective and better tolerated than mesalamine in the treatment of acute ulcerative colitis. Gastroenterology. 1998;114:15-22.

24. Levine DS, Riff DS, Pruitt R, et al. A randomized, double blind, dose-response comparison of balsalazide $(6.75 \mathrm{~g})$, balsalazide $(2.25 \mathrm{~g})$, and mesalamine $(2.4 \mathrm{~g})$ in the treatment of active, mildto-moderate ulcerative colitis. Am J Gastroenterol. 2002;97: 1398-1407. 
25. Green JRB, Gibson JA, Kerr GD, Swarbrick ET, Lobo AJ, Holdsworth CD. Maintenance of remission of ulcerative colitis: a comparison between balsalazide $3 \mathrm{~g}$ daily and mesalazine $1.2 \mathrm{~g}$ daily over 12 months. Aliment Pharmacol Ther. 1998;12: 1207-1216.

26. Green JRB, Swan CHJ, Gibson JA, Kerr GD, Swarbrick ET, Thornton PC. Patient-led variable dosing with balsalazide as long-term therapy for maintenance in ulcerative colitis: a 3-year prospective observational study. Aliment Pharmacol Ther. 2004;19:435-442.

27. MacGregor DJ, Kim YS, Sleisenger MH, Johnson LK. Chemoprevention of colon cancer carcinogenesis by balsalazide: inhibition of azoxymethane-induced aberrant crypt formation in the rat colon and intestinal tumor formation in the B6-Min/+ mouse. Int J Oncol. 2000;17:173-179.

28. Gavrieli Y, Sherman Y, Ben-Sasson SA. Identification of programmed cell death in situ via specific labeling of nuclear DNA fragmentation. J Cell Biol. 1992;119:493-501.

29. Rubin DT, Cruz-Correa MR, Gasche C, et al. Prevention meeting group: colorectal cancer prevention in inflammatory bowel disease and the role of 5-aminosalicylic acid: a clinical review and update. Inflamm Bowel Dis. 2008;14:265-274.

30. Giardiello FM, Hamilton SR, Krush AJ, et al. Treatment of colonic and rectal adenomas with sulindac in familial adenomatous polyposis. $N$ Engl J Med. 1993;328:1313-1316.

31. Steinbach G, Lynch PM, Phillips RK, et al. The effect of celecoxib, a cyclooxygenase-2 inhibitor, in familial adenomatous polyposis. N Engl J Med. 2000;342:1946-1952.

32. Rousseaux C, Lefebvre B, Dubuquoy L, et al. Intestinal antiinflammatory effect of 5-aminosalicylic acid is dependent on peroxisome proliferator-activated receptor-g. J Exp Med. 2005;201: $1205-1215$

33. Gasche C, Goel A, Natarajan L, Boland CR. Mesalazine improves replication fidelity in cultured colorectal cells. Cancer Res. 2005;65:3993-3997.

34. Fukata M, Chen A, Vamadevan AS, et al. Toll-like receptor-4 promotes the development of colitis-associated colorectal tumors. Gastroenterology. 2007;133:1869-1881. 